\title{
Circulating Epstein-Barr virus DNA and cell-free DNA in pediatric lymphomas
}

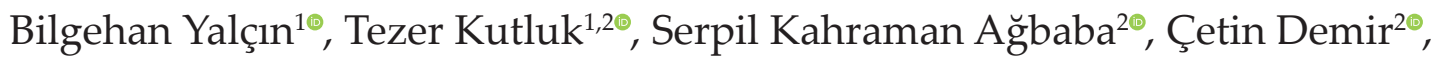 \\ Beril Talim ${ }^{3 \oplus}$ \\ ${ }^{1}$ Department of Pediatric Oncology, Hacettepe University Cancer Institute and Faculty of Medicine; ${ }^{2}$ Drug Resistance Laboratory, \\ Hacettepe University Oncology Hospital, ${ }^{3}$ Department of Pediatrics, Hacettepe University Faculty of Medicine, Ankara, Turkey.
}

\begin{abstract}
Background and objectives. Quantification of serum Epstein-Barr virus (EBV) DNA and/or cell-free total DNA (cf-DNA) may become valuable sources for prognosis evaluation and monitoring treatment response in lymphomas. We aimed to investigate their roles as potential markers in pediatric Hodgkin (HL) and nonHodgkin lymphomas (NHL).

Method. Between the years 2005-2008, 34 patients with HL and 45 with NHL were prospectively included. Serum samples were collected upon diagnosis, after 1-3 and 4-6 months and at the end of treatment, or at disease recurrence. RT-PCR determination of cf-DNA and EBV DNA were performed using amplification of BAMH1W region of EBV genome and of human $\beta$-globin gene. Results were analyzed for correlation with clinical and pathological characteristics.
\end{abstract}

Results. Median ages were 8.9 years for HL and 8.8 years for NHL cases. Twenty-three healthy children cured from various childhood cancers served as the control group. In the controls, median serum EBV DNA copy number was ' 0 ' and median serum cf-DNA level was $50 \mathrm{ng} / \mathrm{ml}$. At initial diagnosis, serum EBV DNA copy numbers were elevated in 20/34 HL and 8/45 NHL cases $(\mathrm{p}<0.001)$. Median serum EBV DNA copy numbers were 15987/mL (125-6032075) and 25162 (1475-1214550) for HL and NHL cases, respectively ( $\mathrm{p}=0.9)$. Median serum cf-DNA levels were $435 \mathrm{ng} / \mathrm{ml}$ (2.3-17306) in HL and $700 \mathrm{ng} / \mathrm{ml}$ (4.9-14009) in NHLs (p=0.12). Serum EBV DNA copy numbers and cf-DNA levels decreased significantly after induction treatment and in the follow-up. In 10/13 NHL cases with a relapse, marked elevations were detected in serum cf-DNA levels at recurrences. No significant differences were detected between median cf-DNA levels according to disease stages, response status to treatment or presence of recurrent disease.

Conclusion. Serum EBV DNA copy numbers and cf-DNA levels were elevated at initial diagnosis in both HLs and NHLs and decreased parallel to treatment response. In NHL cases, remarkable elevation of cf-DNA levels at recurrences indicated that cf-DNA levels might be useful in the follow-up of pediatric NHLs.

Key words: Hodgkin lymphoma, non-Hodgkin lymphoma, serum Epstein-Barr virus, serum cell-free DNA, children.

Tumor-derived DNA is elevated in the serum of patients with cancer. The quantification of circulating Epstein Barr virus (EBV) DNA is reported to have an important role in the diagnosis and management of EBV-associated

$凶$ Bilgehan Yalçın

yalcinb@hacettepe.edu.tr

Received 23rd May 2019, revised 2nd August 2019, accepted 30th August 2019. lymphoid malignancies. ${ }^{1-6}$ Circulating cellfree total DNA (cf-DNA) has been studied in a wide range of physiological and pathological conditions, including pregnancy, trauma, inflammatory disorders and malignancies. ${ }^{7,8}$ Elevated levels of cf-DNA have been reported in many tumour types including pediatric cancers. ${ }^{8-11}$ Both serum EBV DNA and/or cf-DNA may become valuable sources for prognosis evaluation in pediatric lymphomas 
as well as for monitoring treatment response and early identification of recurrences. Few studies have investigated both circulating EBV DNA and total cf-DNA in Hodgkin (HL) and non-Hodgkin lymphomas (NHL). ${ }^{12-14}$ In this study, we aimed to investigate the value of these molecular markers for pediatric lymphomas.

\section{Material and Methods}

During the period between June 2005-November 2008, 34 patients with HL and 45 patients with NHL who were treated with similar standart treatment protocols were prospectively included in the study. Twenty-three healthy children who were cured from various childhood solid cancers other than lymphomas or EBV-related malignancies and were under regular follow-up served as the control group (male/female: 15/8; median age 8.3 years, range 1.7-17.9) to determine the normal range of circulating EBV DNA copy numbers and total cf-DNA. The study was approved by the Ethical Review Board of Hacettepe University (HEK 05/124) and informed consents were obtained from the patients and controls and their parents according to institutional guidelines.

Blood samples were collected from patients upon diagnosis before treatment started, in the follow-up at the end of the induction chemotherapies (1-3 months after diagnosis), at the end of the post-induction chemotherapies (4-6 months after diagnosis), and also at the end of scheduled treatments or at the end of first year after diagnosis; and for some patients when tumor recurrence or progression were suspected or documented.

Serum samples were stored at $-20^{\circ} \mathrm{C}$ and were thawed at room temperature at the time of study. DNA was extracted from $200 \mu \mathrm{L}$ of serum with the QIAamp DNA Blood Mini kit (Qiagen, Germany) according to the blood and body fluid protocol.

Quantitative real-time Polymerase chain reaction (PCR) determination of total cfDNA and EBV DNA were performed using a
Rotorgene PCR cycler (Qiagen, Germany). The assay was based on amplification of BAMH1W region of Epstein-Barr virus genome and of the $\beta$-globin gene of human genome fragments as a housekeeping gene to quantify total cf-DNA. Each PCR run was performed in duplicate and the mean values of results were calculated. Reactions were performed using universal PCR conditions.

Serial dilutions of human genomic DNA (5-log dilution from 50000 to 5 copies $/ \mathrm{mL}$ ) extracted from the EBV-positive Namalwa cell line were used to establish a standard calibration curve. The limit of detection was five copies. Results were expressed as copies of EBV/mL of serum. Each cell was estimated to contain $6.6 \mathrm{pg}$ of DNA and a conversion factor of 2 copies per cell for $\beta$-globin gene was used in order to quantify total cf-DNA levels as $\mathrm{ng} / \mathrm{ml}$. The final results were presented in terms of copies/mL or $\mathrm{ng} /$ $\mathrm{mL}$ in the original serum sample. The results were interpreted for investigating the changes in serum EBV DNA copy numbers and cf-DNA levels and also their correlation with the clinical and pathological characteristics of the patients with HL and NHL. Amplification data were collected and analyzed by Sequence Detection System software (Applied BioSystems, Foster City, CA, USA).

Immunohistochemistry (IHC) for EBV detection was performed on formalin-fixed paraffinembedded tissues from diagnostic biopsies with monoclonal antibodies against LMP-1.

The distribution of various variables between patient groups were compared using $X^{2}$ test. The mean values in the subgroups were compared using $t$-test, and the median values were compared using Wilcoxon, Mann-Whitney-U or Kruskal-Wallis tests. Correlation between sets of data were analysed with Pearson test and linear regression analysis. Overall survival (OS) and event-free survival (EFS) rates were calculated by the Kaplan-Meier method ${ }^{15}$ and differences in survival were compared using the log-rank test. In every instance, a $p$ value $<0.05$ was considered statistically significant. 
For the statistical analyses, PASW Statistics for Windows software (Version 18.0. Chicago: SPSS Inc) was used.

\section{Results}

The median ages were 8.9 years (3.5-17.8; Male/ Female: 25/9) for cases with HL and 8.8 years (1.9-16.5; Male/Female: 37/8) for cases with NHL, respectively. The clinicopathological characteristics of all cases are given in Table I. Histopathological subgroups were as follows: Hodgkin lymphomas: mixed cellularity $(\mathrm{n}=$ 27), nodular sclerosis $(\mathrm{n}=8)$, lymphocyte depletion $(n=2)$, not specified $(n=7)$; nonHodgkin lymphomas: mature B-cell $(n=20)$, lymphoblastic $(\mathrm{n}=15)$, anaplastic large cell $(\mathrm{n}=$
5), and diffuse large B-cell $(n=5)$. In the control group, the median serum EBV DNA copy number was ' 0 ' and median serum cf-DNA level was $50 \mathrm{ng} / \mathrm{ml}$ which were parallel to those reported for healthy individuals. Serum EBV DNA copy numbers $>0$ and serum cf-DNA levels $>50 \mathrm{ng} / \mathrm{ml}$ were accepted as elevated.

\section{Serum EBV DNA copy numbers}

At initial diagnosis, serum EBV DNA copy numbers were elevated in 20/34 (59\%) of HL and $8 / 45(18 \%)$ of NHL cases $(\mathrm{p}<0.001)$. Mean serum EBV DNA copy numbers were $451446 / \mathrm{ml}(-/+$ 1337709) in HLs and $267034 / \mathrm{mL}(-/+431777)$ in NHLs; the median values were $15987 / \mathrm{mL}$ (1256032075) and 25162 (1475-1214550) for HL and NHL cases, respectively $(p=0.9)$.

Table I. Clinicopathological characteristics of children with Hodgkin and non-Hodgkin lymphomas.

\begin{tabular}{|c|c|c|c|c|}
\hline & & $\begin{array}{l}\text { Hodgkin lymphoma } \\
\text { (n) }\end{array}$ & $\begin{array}{l}\text { Non-Hodgkin lymphoma } \\
\text { (n) }\end{array}$ & Total (n) \\
\hline \multirow[t]{4}{*}{ Gender } & Male & 25 & 37 & 62 \\
\hline & Female & 9 & 8 & 17 \\
\hline & Total & 34 & 45 & 79 \\
\hline & $p$ & & 0.35 & \\
\hline \multirow[t]{4}{*}{ Stages of disease } & Localized (I/II) & 16 & 6 & 22 \\
\hline & Disseminated (III/IV) & 18 & 39 & 57 \\
\hline & Total & 34 & 45 & 79 \\
\hline & $p$ & & 0.001 & \\
\hline \multirow[t]{4}{*}{ Serum LDH } & Normal-low & 20 & 19 & 39 \\
\hline & Elevated (>500) & 13 & 25 & 38 \\
\hline & Total & 33 & 44 & 77 \\
\hline & $p$ & & 0.13 & \\
\hline \multirow{4}{*}{$\begin{array}{l}\text { Tumor tissue } \\
\text { EBV LMP1 } \\
\text { (by IHC) }\end{array}$} & Negative & 8 & 21 & 29 \\
\hline & Positive & 22 & 0 & 22 \\
\hline & Total & 30 & 21 & 51 \\
\hline & $p$ & & $<0.001$ & \\
\hline \multirow{4}{*}{$\begin{array}{l}\text { Serum EBV } \\
\text { DNA levels } \\
\text { (copies/mL) }\end{array}$} & Elevated & 20 & 8 & 28 \\
\hline & Negative (‘ $\left.0^{\prime}\right)$ & 14 & 37 & 51 \\
\hline & Total & 34 & 45 & 79 \\
\hline & $p$ & & $<0.001$ & \\
\hline Serum cell-free & Elevated $(>50)$ & 30 & 41 & 71 \\
\hline DNA Levels & Low $(\leq 50)$ & 4 & 4 & 8 \\
\hline \multirow{2}{*}{$(\mathrm{ng} / \mathrm{ml})$} & Total & 34 & 45 & 79 \\
\hline & $p$ & & 0.67 & \\
\hline
\end{tabular}

LDH: lactate dehydrogenase, EBV: Epstein-Barr virus, LMP1: latent membrane protein 1, IHC: immunohistochemistry. 
In 30/34 HL cases immunohistochemistry for Epstein-Barr virus Latent Membrane Protein (EBV LMP1) was studied in the tumor samples, 22 samples $(73 \%)$ were positive and 8 were negative. Serum EBV DNA copy numbers were elevated in 16/22 (72.7\%) cases positive for tumor tissue EBV LMP1 and in 2/8 (25\%) of cases negative for tumor tissue EBV LMP1 ( $p=$ 0.02). Tumor tissue EBV LMP1 was negative in all 21 NHL cases studied.

In both HL and NHL cases, elevated serum EBV DNA copy numbers decreased significantly following induction chemotherapies and in the follow-up. Fig. $1(a, b)$ shows the elevated median serum EBV DNA copy numbers at initial diagnosis and decreases in the followup periods. In 5/34 HL lymphoma cases and in 13/45 NHL cases disease recurrences occurred. No significant increases were detected in the follow-up serum EBV DNA copy numbers of cases who experienced disease recurrences.

In both HL and NHL groups, serum median EBV DNA copy numbers did not differ significantly when the cases were compared according to gender, living in rural or urban towns, initial serum lactate dehydrogenase (LDH) levels being low or high, presence or absence of B symptoms, and the initial chemotherapy response statuses.
Initial serum median EBV DNA copy number was significantly higher in HL cases with advanced stage disease (stages III or IV, 1376/ $\mathrm{mL}$ ) compared to cases with localized disease (stages I and II, 109/mL) ( $p=0.01)$. In HL cases, there was no significant difference between the cases according to the histopathological subtypes for elevation of serum EBV DNA copies. In NHL cases, no significant difference was seen for elevation of serum EBV DNA copies between the groups according to histopathological subtypes, disease stages, and other clinical or laboratory characteristics.

\section{Serum cf-DNA levels}

Mean serum cf-DNA levels were 1290 ng/mL $(-/+3150)$ in HL and $1924 \mathrm{ng} / \mathrm{mL}(-/+700)$ in NHLs $(p=0.35)$, and median levels were 434 $\mathrm{ng} / \mathrm{mL}$ (2.3-17306) in HL and $700 \mathrm{ng} / \mathrm{mL}$ (4.9$14009)$ in NHLs $(p=0.12)$. In the control group, the mean and median serum cf-DNA levels were 82 and $50 \mathrm{ng} / \mathrm{mL}$ (7.8-386), respectively. The differences of median values of serum cfDNA levels in the controls and study patients were significant $(p<0.001$ for both HLs and NHLs). For all HL and NHL cases, a significant correlation was seen between the serum cf-DNA levels and serum LDH levels at initial diagnoses ( $p=0.001$; Pearson R: 0.368)

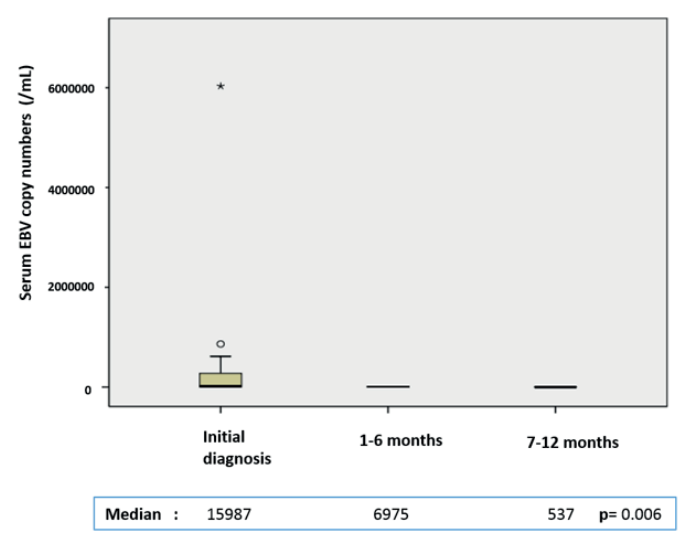

(A)

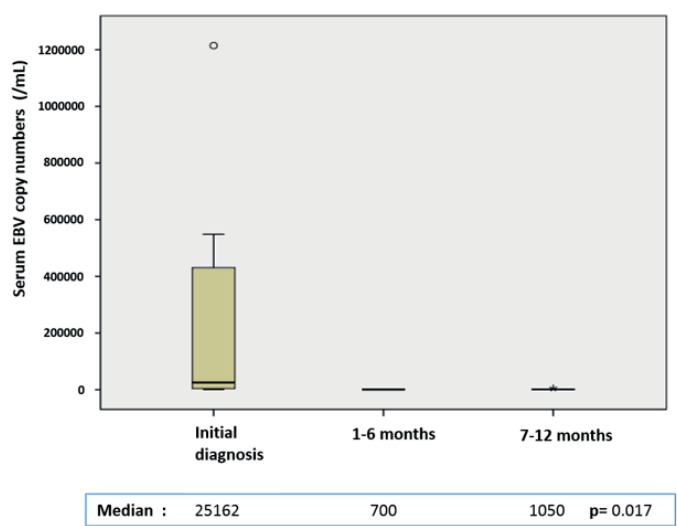

(B)

Fig. 1. Serum EBV DNA levels in 34 Hodgkin (a) and 45 non-Hodgkin lymphoma cases (b). 


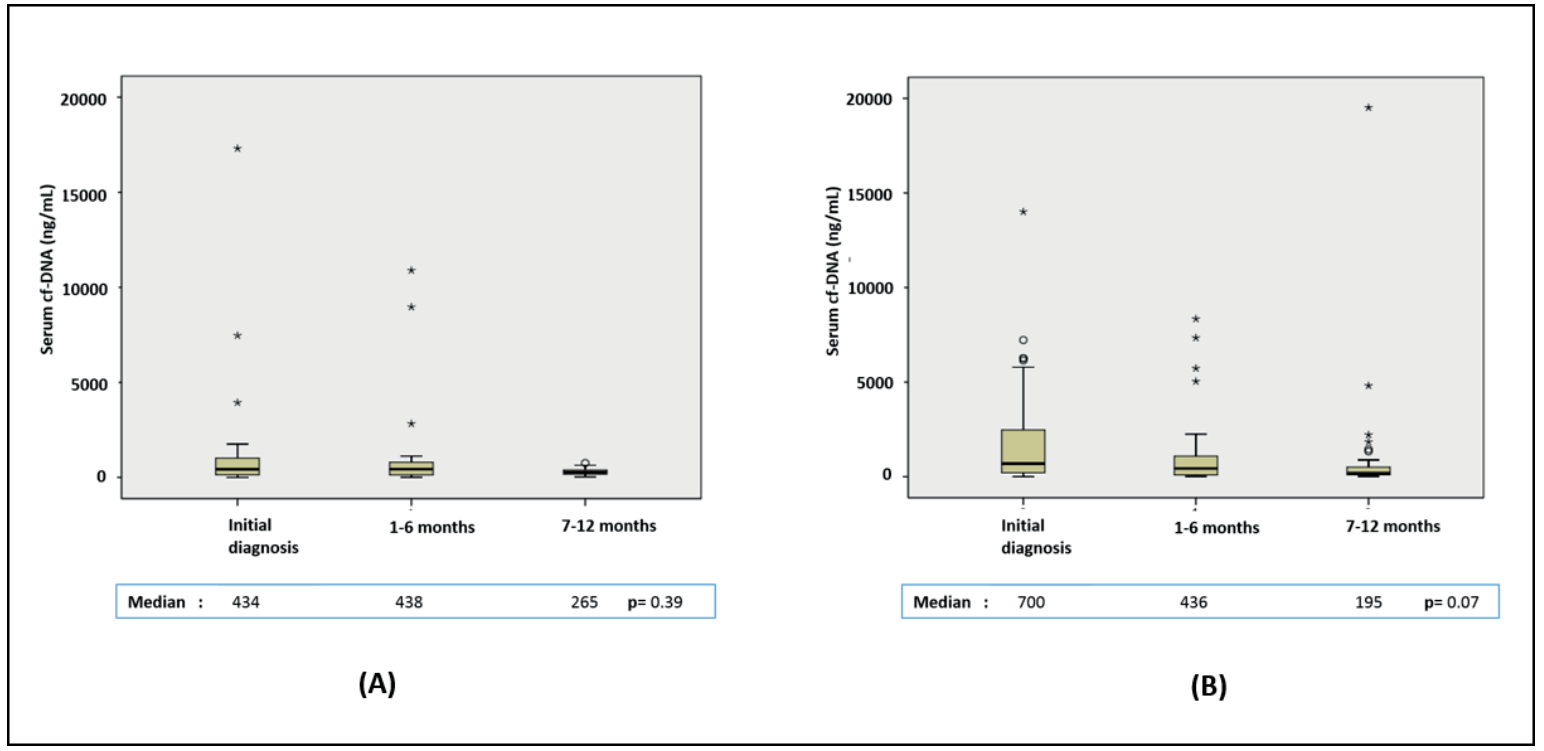

Fig. 2. Serum cf-DNA levels in 34 Hodgkin lymphoma (a) and in 45 non-Hodgkin lymphoma cases (b).

Considering all HL and NHL cases, serum cfDNA levels decreased at the end of induction chemotherapies and in the follow-up. In HL cases, the prospective changes in serum cfDNA levels were less significant compared to NHL cases. Fig. $2(a, b)$ shows the elevated serum cf-DNA levels at initial diagnosis and decreases in the follow-up periods of cases with HL and NHL. In NHL cases who did not have any recurrence of their disease, the decrease in the serum cf-DNA levels was much more significant $(p=0.005)$. The course of serum cfDNA levels in the follow-up of some individual patients with HL or NHL who experienced recurrence of their disease are shown in Fig. 3 (a-f). Ten of 13 NHL cases and 1/5 HL cases who had experienced disease recurrences had simultaneous serum cf-DNA data. In $10 \mathrm{NHL}$ cases the median serum cf-DNA level was 4133 $\mathrm{ng} / \mathrm{mL}$ at initial diagnosis and decreased to 283 $\mathrm{ng} / \mathrm{mL}$ at the end of induction therapies $(\mathrm{p}=$ 0.047 ) which increased to $1079 \mathrm{ng} / \mathrm{mL}$ when recurrences were detected $(p=0.013)$. In cases with or without relapses, median serum cfDNA levels at initial diagnosis were $569 \mathrm{ng} / \mathrm{mL}$ and $406 \mathrm{ng} / \mathrm{mL}(\mathrm{p}=0.77)$ for HL cases, and 1039 $\mathrm{ng} / \mathrm{ml}$ and $699 \mathrm{ng} / \mathrm{ml}(\mathrm{p}=0.44)$ for NHL cases.

In 13/34 HL cases and 11/45 NHL cases, elevated serum cf-DNA levels were detected in the follow-up with no evidence of recurrence or progression (median, $469 \mathrm{ng} / \mathrm{ml}$ ) which were lower than those detected in the relapsed cases at the time of recurrences (median, $838 \mathrm{ng} / \mathrm{ml}$ ) $(\mathrm{p}=0.013)$.

In all lymphoma cases and in HL and NHL cases separately, the differences in the median serum cf-DNA levels were not significant when the cases were compared according to their disease being localized or disseminated, serum LDH levels being low or high, initial chemotherapy response statuses and the presence or absence of recurrent disease. In both HLs and NHLs, the differences in the median serum cf-DNA levels according to histopathological subtypes were not significant.

\section{Survival Analysis}

At a median of 8 years follow-up, 64 cases were alive and under regular follow-up, 10 cases were lost to follow-up and 8 cases died. Five-year event-free (EFS) and overall survival (OS) rates were $82.1 \%$ and $97 \%$ for all HL cases and $68.1 \%$ and $86.4 \%$ for all NHL cases. In HL patients, five-year EFS rate was $78.6 \%$ in cases negative for serum EBV DNA and $79.4 \%$ in cases with elevated serum EBV DNA copy numbers $(\mathrm{p}=$ 0.8 ); five-year EFS rates were $75 \%$ and $82.8 \%$ 


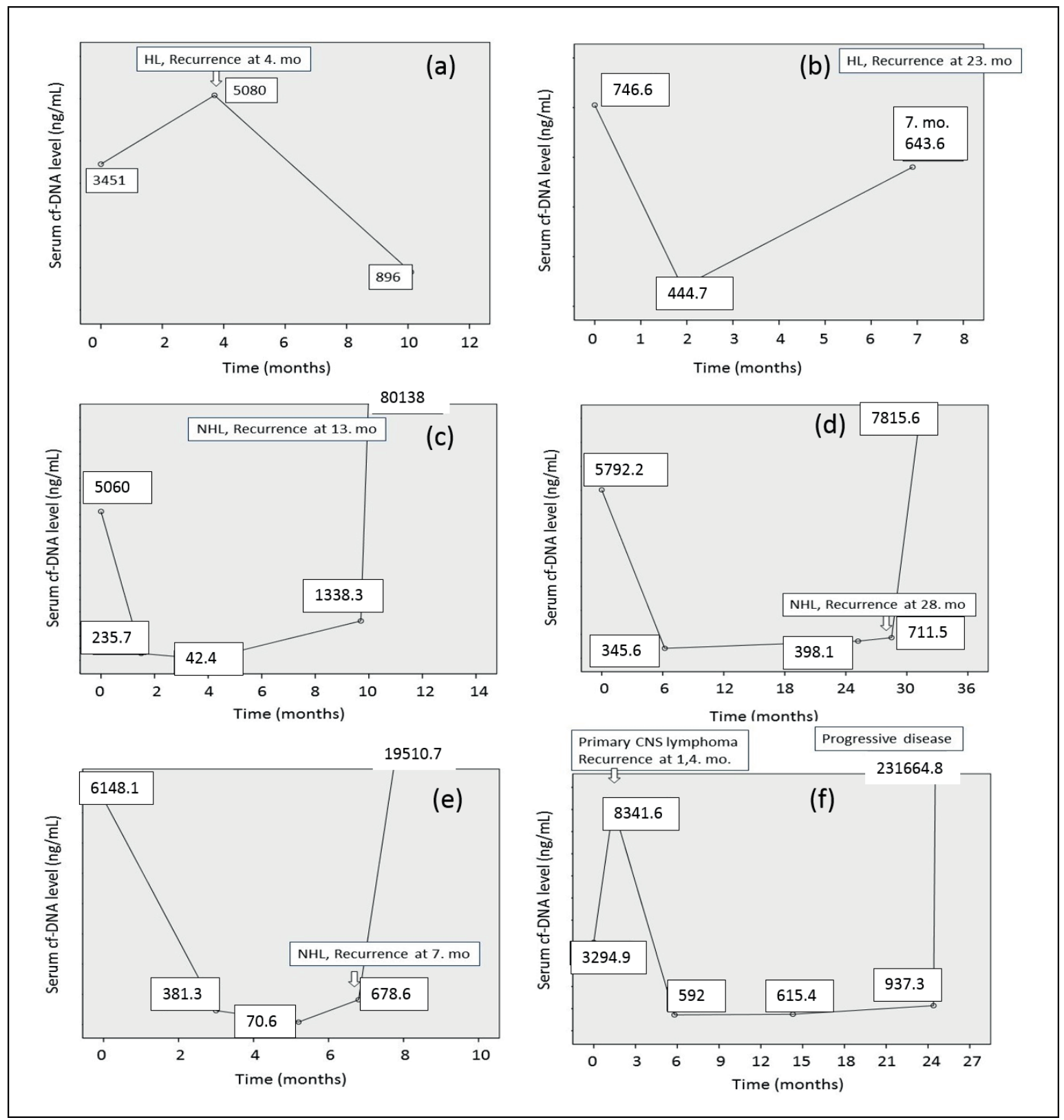

Fig. 3. The course of serum cell-free DNA (cf-DNA) levels in selected Hodgkin (a \& b) and non-Hodgkin lymphoma (c - f) cases who experienced recurrences in the follow-up (HL: Hodgkin lymphoma, NHL: nonHodgkin lymphoma, CNS: central nervous system, mo.: month).

in cases with low serum cf-DNA and elevated serum cf-DNA levels $(p=0.9)$, respectively. In NHL patients, five-year EFS rates were $64.4 \%$ in cases negative for serum EBV DNA and 85.7\% in cases with elevated serum EBV DNA copy numbers ( $p=0.2)$; five-year EFS rates were $66.7 \%$ and $68.6 \%$ in cases with low serum cf-DNA and elevated serum cf-DNA, respectively $(p=0.9)$.

\section{Discussion}

A proportion of childhood lymphomas including HL and Burkitt's lymphoma is associated with EBV and circulating EBV DNA has been detected in the plasma/serum of EBVpositive lymphoma cases. Circulating cell-free EBV DNA has been shown to be useful for early 
detection, prognostication and monitoring of treatment response of nasophayrngeal carcinoma and also is used to guide disease stratification and treatment strategies. ${ }^{16}$

Among patients from the United States and most parts of Europe, approximately $30-50 \%$ HL cases have tumor cells (Hodgkin Reed-Sternbeg - HRS cells ) that harbor the EBV virus. ${ }^{17}$ In contrast, in Turkey and in some countries from Africa and Asia a very high EBV association has been found, with the percentage approaching $100 \% .{ }^{18-20}$ Cavdar et al. ${ }^{18}$ from Turkey reported positivity for EBV by serological and IHC methods in nearly $75 \%$ of children with $\mathrm{HL}$ which is higher than reported from Western countries. The rate of positivity in our study for EBV LMP1 by IHC in HL cases was comparable to their results. Çavdar et al. also reported that in our country children were exposed to EBV at a younger age due to poor living conditions. ${ }^{18}$

\section{Serum EBV DNA copy numbers}

In our study, nearly $3 / 4$ of HL tumor samples were positive for EBV LMP1 by IHC; $72 \%$ of cases with positive IHC had elevated serum EBV DNA compared to $25 \%$ of cases with negative IHC. Similar results have been reported by others. ${ }^{21}$ The strong correlation between the presence of EBV DNA in involved lymph node biopsies and blood samples might suggest that HRS cells are the source of EBV viral DNA. Spacek et al. ${ }^{2}$ reported that circulating free EBV DNA most likely represents tumor derived viral DNA and thus corresponds to disease activity in EBV-positive HL.

In our patients, serum EBV copies were elevated in 59\% of HL cases at initial diagnosis and decreased significantly following induction chemotherapies and in the follow-up as shown in Fig. $1(\mathrm{a}, \mathrm{b})$. However, no significant increases were detected in the EBV DNA copy numbers of cases who experienced disease recurrences.

In several similar studies, circulating EBV DNA has been shown to be elevated at diagnosis and decreased after treatment and was proposed as a biomarker for disease monitoring. ${ }^{1,3,22}$ Thus, our results may indicate that serum EBV DNA can be a parameter to monitor treatment response in EBV-associated pediatric HL. Circulating EBV DNA copy numbers might be undetectable at the time of recurrence in some cases with EBV-related malignancies. The results of our study need to be verified in further studies with higher number of pediatric lymphoma cases.

In our HL cases, the presence of constitutional 'B-symptoms' was not associated with serum EBV DNA viral load at diagnosis. Spacek et al. ${ }^{2}$ also reported no association of 'B-symptoms' with plasma EBV DNA viral load. Serum median EBV DNA copy number was significantly higher in our HL cases with advanced disease which supported the results reported by Musacchio et al..$^{23}$ but contradicted with those of Spacek et al. ${ }^{2}$ and Gandhi et al. ${ }^{1}$

Two separate studies reported that elevated pretreatment blood EBV DNA was associated with poor prognosis in lymphomas..$^{24,25}$ However, we couldn't show any prognostic significance of serum EBV positivity for survival in our HL cases.

Studies examining the serum-plasma EBV status in EBV-related NHLs are rare. In a wide range of EBV-associated lymphoid malignancies, circulating EBV DNA copy numbers have been found to correlate with disease activity and reported to be a useful tumor marker., ${ }^{4,5}$ In $8 / 45$ of our NHL cases who had elevated serum EBV DNA copy numbers, the numbers decreased significantly following chemotherapy as a response to treatment. However, we didn't find any correlation with histopathological subtypes or disease stages.

Lei KI, et al. ${ }^{4}$ reported that plasma EBV DNA was elevated in NHL cases and correlated well with the therapeutic response. In 2013, Kabyemera et al. ${ }^{6}$ reported that EBV load in blood might be a diagnostic and prognostic marker for the onset and monitoring of NHL in African childen.

In our NHL cases who had disease recurrences, no significant increases were detected in 
circulating EBV DNA copy numbers. Serum EBV DNA copy numbers correlated well with response to chemotherapy but our results did not support its use as a follow-up marker for disease monitoring and detection of recurrences.

Machado et al. ${ }^{12}$ reported that circulating EBV DNA was elevated in 7/30 pediatric B-cell NHLs and decrease of EBV viral load was associated with therapy response.

Our results indicated that serum EBV DNA copy numbers can be used as a biomarker of response to treatment in EBV associated HL and NHLs. Since the copy numbers were not elevated in cases with a recurrence of disease, their value for disease monitoring might not be proposed opposite to nasopharyngeal carcinomas.

In our study, serum EBV DNA copy numbers were elevated in 8 cases among all NHL cases. So, it was not possible to perform further subgroup analysis depending on the subtypes of lymphomas.

\section{Serum cf-DNA levels}

Circulating cf-DNA can be found in small amounts in serum of healthy individuals at concentrations between 0 and $100 \mathrm{ng} / \mathrm{ml}$ of blood with an average of $30 \mathrm{ng} / \mathrm{ml} .{ }^{7,9}$ The median level was $50 \mathrm{ng} / \mathrm{mL}$ in our control cases which was similar to these values. In recent years, many studies reported the significance of cf-DNA in the circulation for different cancer types like lung, ovarian and gastrointestinal

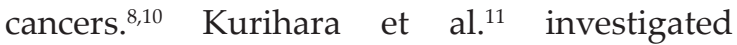
circulating cf-DNA in 44 children with solid tumors who underwent surgical intervention and they concluded that cf-DNA levels were significantly correlated with disease stages. There are few reports available for patients with lymphomas. ${ }^{12-14,26}$

In our study, mean and median serum cf-DNA levels were significantly elevated in both HL and NHL cases compared to controls, the levels being higher in NHLs. Also, the correlation of serum LDH levels with cf-DNA levels was significant. Lactate dehydrogenase is a strong prognostic indicator in lymphomas, elevated levels are correlated with advanced stage and tumor load which indicate poorer prognosis. ${ }^{27}$ Hohaus et al. ${ }^{13}$ reported that increased levels of plasma DNA were associated with advanced stage disease, presence of B symptoms and elevated LDH levels in adult lymphomas. Our study results are in accordance with theirs which might indicate a common mechanism for release of LDH and cf-DNA from the tumor tissues, and also suggest that elevated cf-DNA levels may reflect tumor load.

In our study, serum cf-DNA levels decreased at the end of induction therapies parallel to a decrease in LDH levels being more prominent in NHLs. When the decrease in cf-DNA levels is not prominent or levels remain high, it might indicate the presence of residual or refractory disease. In 10 NHL cases with recurrences, the significantly lowered serum cf-DNA levels at the end of induction therapies were elevated remarkably at the time of recurrences. In some patients with recurrences, serum cf-DNA levels were found elevated long before the detection of recurrences (Fig. 3).

Machado et al. ${ }^{12}$ reported that cf-DNA levels were significantly elevated at diagnosis which declined at the end of treatment. Similarly, Schwarz et al. ${ }^{28}$ reported that in children with lymphoblastic leukemia, high levels of cfDNA were detected in the plasma at diagnosis, decreased rapidly after therapy in few days.

In nearly $1 / 3$ of our lymphoma cases increases in cf-DNA levels were seen with no evidence of recurrence or progression which were less marked compared to increases in cases with recurrences. The release of DNA may also involve other unknown events and increases in the follow-up should be evaluated cautiously with other variables.

Primerano et al. ${ }^{29}$ investigated plasma levels of cf-DNA in a large series of pediatric HLs and reported significantly higher levels compared to controls and proposed that levels of plasma cf-DNA might constitute a non-invasive tool in management of HL patients. In 201 pediatric 
lymphoma cases, Mussolin et al. ${ }^{14}$ found no significant relationship between lymph node histology and cf-DNA levels and no correlation between cf-DNA and B-symptoms, LDH levels or bulky disease. We didn't detect any significant difference between the median serum cf-DNA levels in HLs and NHLs according to histopathological subtypes.

Our results indicate that, although an increased DNA concentration in blood is not specific for a defined disease, quantitative analysis of cfDNA as a noninvasive approach may have a diagnostic value and might be used in the followup of pediatric lymphomas in combination with other clinical and laboratory parameters.

In conclusion, serum EBV DNA copy numbers can be used as a biomarker of response to treatment in pediatric lymphomas. Since the copy numbers were not elevated in cases with a recurrence of disease, their value for disease monitoring might not be proposed. Further prospective studies are required to determine the value of serial circulating EBV DNA monitoring as a predictor of relapse. Serum cf-DNA levels were elevated significantly at initial diagnosis in both HL and NHL cases. Significant decreases were observed in cf-DNA levels when the cases entered remission. Remarkable elevation in serum levels at recurrences in our NHL cases indicated that serum cf-DNA levels can have importance in the follow-up of pediatric NHLs.

\section{Acknowledgement}

This study was supported by a grant from the Turkish Association for Cancer Research and Control.

\section{REFERENCES}

1. Gandhi MK, Lambley E, Burrows J, et al. Plasma Epstein-Barr virus (EBV) DNA is a biomarker for EBV-positive Hodgkin's lymphoma. Clin Cancer Res 2006; 12: 460-464.

2. Spacek M, Hubacek P, Markova J, et al. Plasma EBVDNA monitoring in Epstein-Barr virus-positive Hodgkin lymphoma patients. APMIS 2011; 119: 1016.
3. Dinand V, Sachdeva A, Datta S, et al. Plasma Epstein Barr virus (EBV) DNA as a biomarker for EBV associated Hodgkin lymphoma. Indian Pediatr 2015; 52: 681-665.

4. Lei KI, Chan LY, Chan WY, Johnson PJ, Lo YM. Quantitative analysis of circulating cell-free EpsteinBarr virus (EBV) DNA levels in patients with EBVassociated lymphoid malignancies. Br J Haematol 2000; 171: 239-246.

5. Au WY, Pang A, Choy C, Chim CS, Kwong YL. Quantification of circulating Epstein-Barr virus (EBV) DNA in the diagnosis and monitoring of natural killer cell and EBV-positive lymphomas in immunocompetent patients. Blood 2004; 104: 243249.

6. Kabyemera R, Masalu N, Rambau $P$, et al. Relationship between non-Hodgkin's lymphoma and blood levels of Epstein-Barr virus in children in North-Western Tanzania: a case control study. BMC Pediatr 2013; 13: 4.

7. Anker P, Stroun M. Circulating DNA in plasma or serum. Medicina (B Aires) 2000; 60(5 Pt 2): 699-702.

8. Schwarzenbach H, Hoon DSB, Pantel K. Cell-free nucleic acids as biomarkers in cancer patients. Nat Rev Cancer 2011; 11: 426-437.

9. Leon SA, Shapiro B, Sklaroff DM, Yaros MJ. Free DNA in the serum of cancer patients and the effect of therapy. Cancer Res 1977; 37: 646-650.

10. Vendrell JA, Mau-Them FT, Béganton B, Godreuil S, Coopman P, Solassol J. Circulating cell free tumor DNA detection as a routine tool for lung cancer patient management. Int J Mol Sci 2017; 18: 264.

11. Kurihara S, Ueda Y, Onitake Y, et al. Circulating free DNA as non-invasive diagnostic biomarker for childhood solid tumors. J Pediatr Surg 2015; 50: 2094-2097.

12. Machado ASC, Da Silva Robaina MC, Magalhães De Rezende LM, et al. Circulating cell free and Epstein-Barr virus DNA in pediatric B-non-Hodgkin lymphomas. Leuk Lymphoma 2010; 51: 1020-1027.

13. Hohaus S, Giachelia M, Massini G, et al. Cell-free circulating DNA in Hodgkin's and non-Hodgkin's lymphomas. Ann Oncol 2009; 20: 1408-1413.

14. Mussolin L, Burnelli R, Pillon M, et al. Plasma cellfree DNA in paediatric lymphomas. J Cancer 2013; 4: 323-329.

15. Kaplan EL, Meier P. Non-parametric estimation from incomplete observations. J Am Stat Assoc 1958; 53: 457-481.

16. Zhang W, Chen Y, Chen L, et al. The clinical utility of plasma Epstein-Barr virus DNA assays in nasopharyngeal carcinoma: the dawn of a new era?: a systematic review and meta-analysis of 7836 cases. Medicine (Baltimore) 2015; 94: e845. 
17. Glaser SL, Lin RJ, Stewart SL, et al. Epstein-Barr virus-associated Hodgkin's disease: epidemiologic characteristics in international data. Int J Cancer 1997; 70: 375-382.

18. Cavdar AO, Pamir A, Gözdaşoglu S, et al. Hodgkin disease in children: clinicoepidemiologic and viral (Epstein-Barr virus) analyses. Med Pediatr Oncol 1999; 32: 18-24.

19. Zhou XG, Sandvej K, Li PJ, et al. Epstein-Barr virus (EBV) in Chinese pediatric Hodgkin disease: Hodgkin disease in young children is an EBVrelated lymphoma. Cancer 2001; 92: 1621-1631.

20. Dinand V, Dawar R, Arya LS, Unni R, Mohanty B, Singh R. Hodgkin's lymphoma in Indian children: prevalence and significance of Epstein-Barr virus detection in Hodgkin's and Reed-Sternberg cells. Eur J Cancer 2007; 43: 161-168.

21. Gallagher A, Armstrong AA, MacKenzie J, et al. Detection of Epstein-Barr virus (EBV) genomes in the serum of patients with EBV-associated Hodgkin's disease. Int J Cancer 1999; 84: 442-448.

22. Pajand O, Pourakbari B, Mahjob F, Aghamohammadi A, Mamishi N, Mamishi S. Detection of EpsteinBarr virus DNA in plasma and lymph node biopsy samples of pediatric and adult patients with Hodgkin lymphoma. Pediatr Hematol Oncol 2011; 28: $10-15$.
23. Musacchio JG, Carvalho Mda G, Morais JC, et al. Detection of free circulating Epstein-Barr virus DNA in plasma of patients with Hodgkin's disease. Sao Paulo Med J 2006; 124: 154-157.

24. Park JH, Yoon DH, Kim S, et al. Pretreatment whole blood Epstein-Barr virus-DNA is a significant prognostic marker in patients with Hodgkin lymphoma. Ann Hematol 2016; 95: 801-808.

25. Kanakry J, Ambinder R. The biology and clinical utility of EBV monitoring in blood. Curr Top Microbiol Immunol 2015; 391: 475-499.

26. Jones K, Nourse JP, Keane C, et al. Tumor-specific but not nonspecific cell-free circulating DNA can be used to monitor disease response in lymphoma. Am J Hematol 2012; 87: 258-265.

27. Reiter A, Schrappe M, Tiemann M, et al. Improved treatment results in childhood B-cell neoplasms with tailored intensification of therapy: a report of the Berlin-Frankfurt-Münster Group Trial NHLBFM 90. Blood 1999; 94: 3294-3306.

28. Schwarz AK, Stanulla M, Cario G, et al. Quantification of free total plasma DNA and minimal residual disease detection in the plasma of children with acute lymphoblastic leukemia. Ann Hematol 2009; 88: 897-905.

29. Primerano S, Burnelli R, Carraro E, et al. Kinetics of circulating plasma cell-free DNA in paediatric classical Hodgkin lymphoma. J Cancer 2016; 7: 364 366. 